\title{
A CONSTRUÇÃO DE UMA PEDAGOGIA ANTIRRACISTA COMO ESTRATÉGIA REVOLUCIONÁRIA*
}

Carolina Santos Barroso de Pinho

Este texto tem como objetivo apresentar elementos de uma pedagogia antirracista como estratégia para a transformação social. As ideias aqui apresentadas se alinham àqueles que defendem que o futuro da humanidade depende de uma transformação radical na forma como os seres humanos se relacionam entre si e com a natureza.

Parte-se de dados da realidade que comprovam que o conflito entre os interesses privados e coletivos se acirra na sociedade, portanto, torna-se fundamental a consolidação de estratégias capazes de instrumentalizar o ser humano para a construção de uma sociedade pautada em valores para além do capital. Considera-se que o papel da Educação é imprescindível, tanto para criar estratégias para a transformação, quanto para a elevação do padrão cultural dos grupos oprimidos, como instrumento para a construção de uma nova ordem social.

Diante do papel que o racismo vem desempenhando na sustentação do capitalismo, pode-se concluir que só é possível uma educação para a transformação social se ela se pautar em uma pedagogia antirracista. $\mathrm{O}$ enfrentamento ao capitalismo perpassa pelo enfrentamento ao racismo, uma vez que o segundo é elemento estruturante das relações de destruição que caracterizam o primeiro. Nesse caso, acredita-se que, para além de uma educação para as relações étnico-raciais, é necessária a construção de uma pedagogia que se comprometa com a luta contra o racismo como sistema de poder.

Relações étnico-raciais são aquelas vivenciadas entre os diferentes grupos sociais e as pessoas que compõem esses grupos, munidos de conceitos e ideias das semelhanças e diferenças referentes ao pertencimento racial desses indivíduos e dos respectivos grupos aos

"DOI - 10.29388/978-65-86678-02-4-0-f.31-46 
quais pertencem. Em uma sociedade que foi construída a partir da hierarquização de seres humanos sob o conceito político-ideológico de raça, uma educação para as relações étnico-raciais é um princípio fundamental que vem sendo defendido não apenas por movimentos sociais, mas também por estudiosos das relações étnico-raciais (GOMES; JESUS, 2013), (GOMES, 2012). A luta por uma educação para as relações étnico-raciais contou com vitórias importantes do ponto de vista de políticas públicas, como a aprovação da Lei 10639/03 e da Lei 12711/12 (instituiu a reserva de vagas em Instituições Federais de Ensino). Entretanto, estimativas demonstram que as políticas de ações afirmativas voltadas para a população negra, que incluem a educação das relações étnico-raciais, ainda não são suficientes. Ou seja, a superação do racismo perpassa por políticas públicas de educação das rela ções étnico-raciais, mas depende de uma luta que confronte as estruturas sociais. Na essência, isso dá sentido ao pensamento de Angela Davis (2018), que defende a centralidade da luta contra o racismo, para além de um posicionamento não racista.

Diante dessas considerações, construí este texto em duas partes. Na primeira, são apresentados dados que comprovam que o racismo estrutura a sociedade capitalista e que, portanto, uma luta contra o capitalismo deve ser uma luta antirracista. Na segunda parte, são apresentadas possibilidades teóricas que podem embasar uma pedagogia antirracista como fundamento da transformação social. Kilomba (2019), Mesquita (2019), hooks (2019, 2013), Collins (1990), Silva (2007), Cavallero (2001) são algumas das autoras que oferecem subsídios para defender que a transformação radical na sociedade perpassa pela atitude política de combate ao racismo dentro e fora de sala de aula.

\section{Capitalismo e racismo: elementos conjunturais}

A humanidade vive em um tempo histórico configurado por uma profunda crise no sistema social, que se estrutura sob o nome de capitalismo. Apesar de a humanidade ter desenvolvido, em uma po- 
tência surpreendente, as formas de produzir riqueza, essa riqueza é produzida por muitos, mas apropriada por poucos. Há indícios muito sérios de que a humanidade não se sustenta mais diante dessa desigualdade sem precedentes.

As condições de vida da maior parte da população mundial confirmam esta tese. Ainda que o ser humano tenha produzido conhecimentos para visitar outros planetas, ainda há centenas de mortes de crianças no mundo por falta de alimento. Mais de um bilhão de pesso as passam fome em pleno século XXI. A fome mata uma criança a cada cinco segundos no mundo. No entanto, já foi comprovado que existem alimentos disponíveis para alimentar toda a população mundial. Quando se sabe que $85 \%$ dos alimentos no mundo são controlados por dez empresas, facilmente se conclui que a especulação financeira é a principal causa da falta de alimentos. As empresas que monopolizam a produção de alimentos decidem quem vai comer ou quem vai morrer de fome. (COUTINHO JUNIOR, 2013)

Nem mesmo os países que gerenciam o imperialismo ${ }^{1}$ - especialmente os Estados Unidos - têm conseguido assegurar o mínimo necessário à sobrevivência dos trabalhadores em suas nações. Após o esgotamento do Welfare State - Estado de Bem-Estar Social - e do modelo Fordista/Taylorista de produção, que foram implantados a partir da crise de superprodução de 1929, a crise estrutural apenas se aprofundou. Nem mesmo os ajustes do neoliberalismo foram capazes de tirar o capitalismo de sua crise. O neoliberalismo pauta-se, sobretudo, na defesa irrestrita da liberdade individual, como consequência da liberdade do mercado - livre circulação do capital - frente a qualquer tipo de intervenção estatal.

Dados da realidade comprovam que as políticas implementadas pela agenda neoliberal não aliviaram a crise estrutural do sistema capitalista. Na primeira década dos anos 2000, explodiu a bolha imobiliária dos Estados Unidos da América (EUA). Mundialmente, essa crise ficou conhecida como "crise do subprime", nome dado ao crédito

\footnotetext{
${ }^{1}$ Imperialismo é a política exercida por um Estado que visa à própria expansão, por meio de aquisição territorial ou pela submissão econômica, política e cultural de outros Estados.
} 
de risco do setor imobiliário dos EUA, e acabou atingindo diretamente o setor produtivo e financeiro em escala mundial. No ano de 2007, quase dois milhões de pessoas nos EUA não conseguiram pagar o financiamento de seus imóveis e foram despejadas. Com tanta inadimplência, causada pelas altas taxas de juros e endividamento, os bancos e as seguradoras quebraram, assim como os especuladores que haviam comprado dívidas dos créditos hipotecários e que lucravam com a supervalorização dos imóveis. Resultado: O Estado teve que intervir para salvar os bancos, contrariando a cartilha neoliberal.

O Programa das Nações Unidas para o Desenvolvimento (PNUD) e a Iniciativa sobre Pobreza e Desenvolvimento Humano de Oxford (OPHI na sigla em inglês) elaboram anualmente o Índice Global de Pobreza Multidimensional. A edição de 2019 lembra que existe 1,3 bilhão de pessoas multidimensionalmente pobres nos cento e um países de renda baixa e média que o estudo analisa, ou seja, que sofrem várias carências de uma lista de dez tipos relacionadas à Saúde, Educação e qualidade de vida. Além dessas pessoas, há aqueles 736 milhões considerados extremamente pobres, que vivem com menos de 1,90 dólar (cerca de 7,07 reais) por dia.

Os dados acima demonstram que os seres humanos estão sendo destruídos no sentido literal da palavra. Mas, a natureza também. A natureza não suporta mais as relações destrutivas entre ser humano e o meio ambiente e mostra sinais de colapso. A saída dos Estados Unidos do Acordo de Paris mostra que a prioridade das grandes potências econômicas é o lucro. Mesmo sendo a nação que mais produz danos à natureza no mundo, os Estados Unidos se recusam a se comprometer com a redução da emissão de gases na natureza. Até mesmo a União das Nações Unidas já reconhece que "Os padrões atuais de consumo, produção e desigualdade não são sustentáveis” e indica que é urgente que sejam tomadas medidas essenciais, tais como: reduzir a degradação da terra, a perda de biodiversidade e a poluição do ar, da terra e das águas; melhorar a gestão da água, mitigar a mudança climática e reduzir a queima de combustíveis fósseis. 
Obviamente, nesse quadro há aqueles que são mais atingidos e expostos às pressões políticas e econômicas. O mesmo Índice Global de Pobreza Multidimensional aponta que as pessoas que mais sofrem com a pobreza no mundo são as mulheres, as negras, os negros e a população LGBT, especialmente aqueles que vivem no sul do globo.

No Brasil, dados comprovam que negras e negros são os mais atingidos pelo aprofundamento da crise capitalista. No mercado de trabalho, dados recentes divulgados pelo IBGE mostram que a população negra ganha 59\% dos rendimentos de pessoas brancas. Além disso, negras e negros representam 70\% da população que vive em situação de extrema pobreza, concentram maiores taxas de analfabetismo do que brancos - $11 \%$ entre negros e $5 \%$ entre brancos, além de constituí rem mais de $61 \%$ da população encarcerada, embora representem $54 \%$ da população (IBGE). O que é oferecido como solução, assim como no resto do mundo, são medidas que visam garantir privilégios e ampliar as desigualdades. Toma-se como exemplo a reforma trabalhista. Aprovada em 2017 como uma "modernização da legislação trabalhista" é um retrocesso que atinge em cheio a população negra. Entre as principais mudanças estão, por exemplo, i. a flexibilização do tempo para o contrato de trabalho de carga horária parcial, que por sua vez diminui na mesma proporção o salário, e culmina em uma maior vulnerabilidade social; ii. o afastamento da legislação relativa ao trabalho formal (CLT) em casos que envolvam o labor informal; iii. a permissão legislativa do trabalho de grávidas e lactantes em lugares de insalubridade média ou mínima, devendo apresentar pedido médico formal para afastamento; iv. os danos morais cobrados por empregadas devem ser proporcionais ao salário recebido por elas; e, por fim, v. a revogação do descanso de quinze minutos para as mulheres antes que elas iniciem suas horas extras. A diminuição do horário de descanso e a facilidade de contratação sem vínculos devem atingir principalmente a quem já está mais vulnerável, que são aqueles que têm menos poder de negociação de sua forca de trabalho e acabam sendo empurrados para as piores situações. 
Segundo Gomes (2018), quando se concentra a atenção na juventude, etapa importante na trajetória social e identitária da sociedade, o que se vê é uma sentença de morte que se articula perversamente por meio do racismo e da vulnerabilidade social. Segundo o Atlas da Violência (2017), de cada cem pessoas que sofrem homicídio no Brasil, setenta e uma são negras. "Jovens e negros do sexo masculino continuam sendo assassinados todos os anos como se vivessem em situação de guerra" (p. 30). Os dados do Atlas confirmam que ser negro no Brasil é um fator de risco determinante. Pode-se comprovar essa afirmação com a análise da evolução das taxas de homicídios considerando se o indivíduo era negro ou não, entre 2005 e 2015. Enquanto, nesse período, houve um crescimento de $18,2 \%$ na taxa de homicídio de negros, a mortalidade de indivíduos não negros diminuiu 12,2\%.

O Índice de Vulnerabilidade Juvenil à Violência 2017 (BRASIL, 2017), ao trazer o recorte de gênero pela primeira vez, revela que as jovens negras com idade entre 15 e 29 anos têm 2,19 vezes mais chances de serem assassinadas no Brasil do que as brancas na mesma faixa etária. No mesmo sentido, o Atlas da Violência (2017) mostrou que entre 2005 e 2015 a taxa de homicídios de mulheres brancas teve redução de $7,4 \%$, enquanto a taxa de mortalidade de mulheres negras aumentou $22 \%$. O recorte de gênero ajuda a visualizar a distribuição da violência que recai sobre a mulher negra, sobretudo as jovens, e permite, inclusive, indagar a respeito da incidência do feminicídio negro juvenil nos dados levantados.

Os dados apresentados acima comprovam que, apesar da melhoria de vida da população devido às políticas realizadas no período de 2005 a 2015, a violência letal recai com maior incidência sobre a população negra. O que permite inferir que o aprofundamento da crise do capitalismo tem levado ao acirramento de conflitos raciais, devido ao lugar social que foi reservado às pessoas negras na sociedade de classe.

Com a ofensiva do capital, entre o lucro e a vida dos mais vul neráveis, o que importa é o lucro. Para garantir o lucro, a vida de trabalhadores e trabalhadoras é supérflua. Sabendo que classe trabalha- 
dora no Brasil é formada em sua maioria por pessoas negras, a vida de negras e negros é aquela que tem menos valor. Constata-se que o genocídio da população negra é, portanto, uma política de Estado cada dia mais marcante no capitalismo. Comprova-se que o racismo é elemento estruturante do sistema capitalista. Assim, pode-se concluir que em um momento em que o capitalismo agoniza, ele vai aprofundar a violência racista nas relações pessoais e também nas instituições (GOMES, 2018)

O embricamento entre capitalismo e racismo leva a uma conclusão: a luta por uma transformação social radical só pode ser construída como possibilidade se ela tiver compromisso com a luta antirracista.

\section{Pedagogia antirracista como estratégia revolucionária}

Os elementos conjunturais apresentados são fundamentais para a reflexão a respeito de uma educação comprometida com a transformação social que parece ser cada dia mais urgente. Diante de uma crise que ameaça a existência humana como espécie, a tarefa de uma educação crítica é construir estratégias e condições para um futuro digno para a humanidade.

No tocante ao papel da educação, Saviani (2012) defende que a educação visa à promoção do ser humano. Como promoção do ser humano, o autor compreende a capacidade humana de conhecer os elementos de sua situação para intervir nela, transformando-a no sentido de uma ampliação da liberdade, da comunicação e colaboração entre seres humanos. Assim, uma pedagogia para a transformação social, como uma teoria educacional sistematizada, que busca solucionar o problema da relação educador-educando, só é possível se for comprometida com a luta antirracista. Só é possível uma pedagogia transformadora se ela for também uma pedagogia antirracista.

Como teoria educacional, uma pedagogia antirracista se constrói a partir da dialética dos conflitos raciais no momento histórico em que vive, apontando para a sociedade livre de opressões que se quer 
construir. Ou seja, ela não é uma utopia e sim uma pedagogia concreta. Para Saviani (2012), uma pedagogia concreta é aquela que considera os educandos como indivíduos concretos, que são a síntese de rela ções sociais.

Dois elementos fundamentais podem ser destacados, engendrados dialeticamente nas relações racistas e que podem mediar a construção de uma pedagogia antirracista. O primeiro elemento é a racialização da teoria educacional. Sabe-se que o conceito de raça é uma categoria sociológica que veio sendo construída a partir das relações de poder instituídas entre os seres humanos, e que foi determinada pela estrutura capitalista como justificativa para as relações de extermínio e exploração promovidas pela branquitude ${ }^{2}$. Segundo Achille Mbembe (2018, p.28-29):

A raça não existe enquanto fato natural físico, antropológico ou genético. A raça não passa de uma ficção útil, uma construção fantasmática ou uma projeção ideológica, cuja função é desviar a atenção de conflitos considerados, sob outro ponto de vista, como mais genuínos - a luta de classes ou a luta de sexos, por exemplo [...]. Em sua ávida necessidade de mitos destinados a fundamentar seu poder, o hemisfério ocidental considerava-se o centro do globo, a terra natal da razão, da vida universal e da verdade da humanidade. Sendo o rincão mais "civilizado" do mundo, só o Ocidente foi capaz de inventar um "direito das gentes". Só ele conseguiu edificar uma sociedade civil das nações compreendida como um espaço público de reciprocidade do direito. Só ele deu origem a uma ideia de ser humano dotado de direitos civis e políticos, permitindo-lhe exercer seus poderes privados e públicos como pessoa, como cidadão pertencente ao gênero humano, e enquanto tal, interessado por tudo que é humano.

\footnotetext{
${ }^{2}$ Ver mais em BENTO, M. A. S. Branqueamento e branquitude no Brasil. In: CARONE, I.; BENTO, M. A, S. Psicologia Social do Racismo: estudos sobre branquitude e branqueamento no Brasil. Petrópolis: Vozes, 2002. p. 25-57.
} 
Portanto, ainda que se saiba que biologicamente não há raças humanas, a racialização do ser humano foi produzida nas relações de poder ao longo da história. Para Mbembe (2018, p.69), na sociedade "a raça não decorre somente de um efeito ótico. Não diz respeito unicamente ao mundo sensorial". É também uma maneira de estabelecer e de afirmar o poder.

Para pensar em uma pedagogia antirracista é necessário reconhecer as múltiplas dimensões que sustentam as relações de poder capitalistas. Para a manutenção do status quo, durante a história, a burguesia lançou mão de opressões de gênero, raça, sexualidade, territorialidade $^{3}$. Uma pedagogia antirracista deve assumir que o conceito social de raça é eixo que estrutura as relações capitalistas e, assim, estrutura as relações sociais sob as quais as teorias se constroem. Por isso, em uma educação antirracista é fundamental compreender que todos os indivíduos foram racializados em sua socialização, e por isso experienciam lugares sociais de privilégio, quando brancos, ou de subalternidade quando não brancos. Racializar a teoria educacional significa assumir raça como categoria de análise na construção de uma pedagogia revolucionária porque permite que se possa desconstruir o mito da democracia racial $^{4}$ e construir uma educação para as relações étnico-raciais.

Um segundo elemento que pode mediar a construção de uma pedagogia antirracista é a ressignificação do que é ser negro. Considerando que os sujeitos foram racializados e, como tal, experienciam o que foi construído socialmente como raça, desconstruir os significados

\footnotetext{
3 Alguns estudos no campo da educação têm se pautado na categoria interseccionalidade. Segundo Mesquita (2019, p.49), essa categoria "abarca o reconhecimento das múltiplas dimensões que constituem as identidades e experiências sociais dos sujeitos". É uma elaboração teórica que vem sendo construída no movimento feminista negro. Para saber mais sobre interseccionalidade, ver CRENSHAW, Kimberlé W. Demarginalizing the intersection of race and sex- a black feminist critique of discrimination doctrine, feminist theory and antiracist politics. University of Chicago Legal Forum, 1989.

${ }^{4}$ Segundo Mesquita (2019), o mito da democracia racial pode ser considerado como fundamento do discurso nacional, a partir do Estado Novo. Esse mito nada mais é do que a ideia propagandeada de que o Brasil é um país em que as raças convivem pacificamente, uma vez que o país é miscigenado.
} 
hierárquicos atribuídos às raças é fundamental para uma pedagogia antirracista. Em $A$ invenção do ser negro (2002), Santos apresenta o percurso das ideias que naturalizaram a inferioridade dos negros. A autora identifica diversas justificativas utilizadas na história para subalternizar pessoas negras, inclusive pautadas em uma pseudociência ancorada em métodos derivados da Biologia, Medicina e Fisiologia. No século XIX, toda desigualdade social se apoiava na diversidade biológica dos seres humanos. Essa diversidade foi utilizada para hierarquizar os seres humanos.

No Brasil, o Estado recorreu ao racismo para construir uma identidade nacional baseada na miscigenação. Na verdade, essa "construção da identidade nacional" foi pano de fundo para um branqueamento da população, uma vez que o projeto de edificação de uma imagem negativa da pessoa negra constituiu os primórdios das relações sociais no país. Como um país que foi constituído a partir da mão de obra de negras e negros escravizadas/os e que depois da abolição foram abandonadas/os à própria sorte, o Brasil teve como estrutura ideológica de sua cultura a imagem da pessoa negra como alguém desprovido de beleza estética, material e moral.

Considerando o papel da educação como agente responsável pela promoção da elevação cultural do repertório humano, para que ele possa compreender e intervir na realidade, pode-se concluir que a ressignificação do que é ser negro e, portanto, do que é ser branco, em uma sociedade com bases racistas, é uma tarefa também da escola. Uma pedagogia antirracista deve se preocupar em promover a reconstrução da história dos descendentes de escravizados para que eles se compreendam como agentes de sua própria história, em um processo de emancipação e tomada de poder. Como efeito imediato, o que se espera de um movimento de ressignificação do ser negro é a inserção de valores étnico-culturais do povo negro e suas contribuições para a formação do povo brasileiro. Do ponto de vista histórico, é um dos passos fundamentais para a construção de um espírito de luta capaz de impulsionar indivíduos negros e negras a se engajarem pela transformação social. 
É nesse contexto que a luta pela implementação e cumprimento da lei 10639/03, que institui o ensino de História da África e cultura africana e afro-brasileira nos currículos da Educação Básica, se inseriu. Segundo Barbosa (2017), a luta do movimento negro por uma educação antirracista não é recente e a reivindicação pela inclusão do ensino de história da África e da Cultura afro-brasileira nas escolas foi um processo marcado por algumas iniciativas, como a Lei apresentada pelo então deputado Abdias do Nascimento, em 1983, o projeto de Paulo Paim, em 1988, de deputada Benedita da Silva, em 1988, 1993 e 1995, do deputado Humberto Costa, em 1995. Apesar de não terem sido aprovadas, tais propostas foram importantes para impulsionar esta discussão e construir capital político para a aprovação da Lei $10.639 / 2003$, que foi alterada pela Lei $11.645 / 2008$, que dispõe sobre o estudo de história e cultura afro-brasileira e indígena nos estabelecimentos de ensino fundamental e médio, públicos e privados no Brasil. Ainda segundo Barbosa (2017), a aprovação da Lei no 10.639, em 2003, favoreceu o debate a respeito das questões étnico-raciais dentro e fora dos espaços educativos; entretanto, apesar de ser uma política de Estado, ainda não foi amplamente implementada em todos os níveis de ensino.

Gomes (2018) identifica outra manifestação que compõe o processo de reconstrução da história do povo negro. A partir da racialização, há uma movimentação protagonizada por jovens negros. Apesar de não acontecer apenas na educação formal, jovens negros têm transformado o significado histórico dado à raça negra, ressignificando-a como símbolo de afirmação, de luta e emancipação. É um movimento expresso através de cabelos crespos naturais, valorização de religiões de matriz africana e da cultura afrodiaspórica. A ocupação de vagas nas universidades, o empreendedorismo negro e juvenil, principalmente no mundo da comunicação e do design, são alguns dos espaços que têm sido tomados por jovens negros que têm levado a esses espaços a denúncia: Parem de nos matar.

Esses elementos aparecem como pistas em proposições pedagógicas formuladas por Cavallero (2001) e hooks (2019). Cavallero 
(2001) elenca oito aspectos que podem ser reconhecidos quando se fala em uma proposta de Educação antirracista em favor da igualdade:

1. Reconhece a existência do problema racial na sociedade brasileira.

2. Busca permanentemente uma reflexão sobre o racismo e seus derivados no cotidiano escolar.

3. Repudia qualquer atitude preconceituosa e discriminatória na sociedade e no espaço escolar e cuida para que as relações interpessoais entre adultos e crianças, negros e brancos sejam respeitosas.

4. Não despreza a diversidade presente no ambiente escolar: utiliza-a para promover a igualdade, encorajando a participação de todos/as os/as alunos/as.

5. Ensina às crianças e aos adolescentes uma história crítica dos diferentes grupos que constituem a história brasileira.

6. Busca materiais que contribuam para a eliminação do 'eurocentrismo' dos currículos escolares e contemplem a diversidade racial, bem como o estudo de 'assuntos negros'.

7. Pensa meios e formas de educar para o reconhecimento positivo da diversidade racial.

8. Elabora ações que possibilitem o fortalecimento do autoconceito de alunos e de alunas pertencentes a grupos discriminados (CAVALLERO, 2001, p. 158).

Para Bell Hooks (2019), diante da realidade atual, é necessário um conjunto de princípios que configuram o que a autora chama de pedagogia feminista negra, em que ela toma como referência a obra de Paulo Freire (1967) e a "educação para a prática da liberdade",

1. Negação da neutralidade: é necessário tomar posição política. Não existe neutralidade em uma realidade em que há, explicitamente, uma luta por sobrevivência x por lucro.

2. Compromisso com a luta pela transformação social: a luta antirracista é uma luta revolucionária. "A pedagogia feminista só pode ser libertadora se for verdadeiramente revolucionária, pois os mecanismos de apropriação dentro do pa- 
triarcado de supremacia branca e capitalista são capazes de cooptar com tremenda facilidade o que meramente parece radical ou subversivo"

3. União entre teoria e prática: a sala de aula deve ser um lugar em que o senso de luta tem lugar de privilégio.

4. Livrar-se das pedagogias tradicionais: não é possível se filiar às pedagogias tradicionais quando optamos por um posicionamento político explícito.

5. É necessário refletir sobre a relação de poder entre aluno / professor. É óbvio que existe uma relação de poder instituída. Mas, o que deve ser questionado é: como esse poder é utilizado? Usamos o poder para diminuir ou enriquecer as relações de domínio instituídas socialmente?

6. Questionar os modelos tradicionais de avaliação: A avaliação reflete um modelo de ensino. Não é possível pensar os modelos de avaliação que se pautem pela transformação social, considerando modelos de ensino que se pautem em pedagogias tradicionais.

7. Definir os termos dos compromissos: a negação da neutralidade pressupõe acordos explícitos. Alunos e professores devem saber que aquela sala de aula é organizada a partir de uma pedagogia revolucionária.

8. Encorajar os alunos a transformarem-se a partir do que estão aprendendo em sala de aula. Para uma pedagogia feminista revolucionária precisamos de feministas revolucionárias. É necessário incentivar a transgressão, o questionamento e o resgate do espírito de risco.

A luta pela transformação social não é uma tarefa fácil e nem individual. Ela requer compromisso político de luta daqueles que identificam que é possível uma sociedade sem classes e opressões. Por isso, é urgente a construção de uma agenda que coloque como prioridade uma transformação radical na sociedade, não apenas por meio de uma atitude teórica e reflexiva, mas de uma atitude política de compromisso com a melhoria real da vida das pessoas, principalmente àquelas que estão em situação de maior vulnerabilidade, como a popu- 
lação negra, que ainda carrega a marca de mais de trezentos anos de escravidão. Esse é o caráter da luta antirracista dentro e fora da escola.

\section{Referências}

BARBOSA, B. R. Racismo, educação superior e formação antirracista: o caso do curso de pedagogia da Universidade de Campinas. Revista Eletrônica Científica Ensino Interdisciplinar - RECEI. Mossoró, v.3, n.9, 2017.

BENTO, M. A. S. Branqueamento e branquitude no Brasil. In: CARONE, I.; BENTO, M. A, S. Psicologia Social do Racismo: estudos sobre branquitude e branqueamento no Brasil. Petrópolis, Vozes, 2002. p.25-57.

BRASIL. Presidência da República. Secretaria de Governo. Índice de vulnerabilidade juvenil à violência 2017: desigualdade racial, municípios com mais de 100 mil habitantes. Secretaria de Governo da Presidência da República, Secretaria Nacional de Juventude e Fórum Brasileiro de Segurança Pública. São Paulo: Fórum Brasileiro de Segurança Pública, 2017.

BRASIL. Lei 13.467 de 13 de julho de 2017. Altera a Consolidação das leis do trabalho (CLT), aprovada pelo Decreto-Lei N. 5452, de $1^{\circ} \mathrm{de}$ maio de 1943, e as leis $\mathrm{n}^{\circ} 6.019$, de 3 de janeiro de 1974, 8.036 de 11 de maio de 1990, e 8.212 de 24 de julho de 1991, a fim de adequar a legislação à novas relações de trabalho. Disponível em: < http://legislacao.planalto.gov.br/legisla/legislacao.nsf/Viw Identificacao/lei\%2013.467_2017? OpenDocument>. Acesso em: 15 jan. 2020.

BRASIL. IBGE. Pesquisa Nacional por amostra de domicílios, 2016. IBGE, 2016

CAVALLERO, Eliane. Educação anti-racista: compromisso indispensável para um mundo melhor. In: Racismo e Anti-racismo na educação: repensando a escola. São Paulo: Selo Negro, 2001. p.141-160. 
CERQUEIRA, D.; LIMA, R. S. de; BUENO, S. et al. Atlas da violência 2017. Rio de Janeiro: IPEA-FBSP, 2017.

COUTINHO JÚNIOR, J. Especuladores devem ser julgados pela fome. Brasil de Fato, São Paulo, 14 mai. 2013. Disponível em: Acesso em: 19 jan. 2020.

COLLINS, Patricia Hill. Pensamento feminista negro: conhecimento, consciência e a política do empoderamento. Trad. Natália Luchini. Seminário "Teoria Feminista", Cebrap, 2013. [Em inglês, Black feminist thought: knowledge, consciousness, and the politics of empowerment.] Nova York/Londres: Routledge, 1990.

CRENSHAW, Kimberlé. Documento para o encontro de especialistas em aspectos da discriminação racial relativos ao gênero. Estudos feministas. 1, p.171-189, 2002.

DAVIS, Angela. A liberdade é uma luta constante - Ferguson, Palestina e as bases para um movimento. São Paulo: Barat Frank, Boitempo, 2018.

FREIRE, Paulo. Educação como Prática da Liberdade. Rio de Janeiro: Paz e Terra, 1967.

GOMES, Nilma Lino; LABORNE, Ana Amélia de Paula. Pedagogia da crueldade: racismo e extermínio da juventude negra. Educ. rev., Belo Horizonte, v. 34, e197406, 2018. Available from < http://www.scielo.br/scielo.php?script $=$ sci arttext\&pid $=$ S010246982018000100657\&lng=en\&nrm=iso $>$. access on 11 Feb. 2020. Epub Nov 23, 2018. http://dx.doi.org/10.1590/0102-4698197406>. Acesso em: 11 fev. 2020.

GOMES, N. L. Relações étnico-raciais, educação e descolonização dos currículos. Currículo sem Fronteiras, v. 12, n. 1, jan./abr. 2012.

GOMES, N. L.; JESUS, R. E. As práticas pedagógicas de trabalho com relações étnico-raciais na escola na perspectiva da Lei 10.639/2003: desafios para a política educacional e indagações para a pesquisa. Educar em Revista, Curitiba: Editora da UFPR, n. 47, jan/mar. 2013. 
Hooks, B. Ensinando a transgredir. São Paulo: Martins Fontes, 2013. Olhares Negros: raça e representação. São Paulo: Editora Elefante, 2019.

KILOMBA, Grada. Memórias da plantação: Episódios de racismo cotidiano. Rio de Janeiro: Cobogó. 2019.

MBEMBE, Achille. Crítica da Razão Negra. Tradução de Sebastião Nascimento. São Paulo: n-1 edições, 2018. 320p.

MESQUITA, Tayná Victória de Lima. Exclusão escolar racializada: implicações do racismo na trajetória de educandos da EJA. Jundiaí: Paco Editorial, 2019.

SANTOS, Gisleine A. A invenção do ser negro: um percurso das ideias que naturalizaram a inferioridade dos negros. São Paulo: Pallas, 2002.

SAVIANI, Dermeval. Educação: do senso comum à consciência filosófica. Campinas, SP: Editores Associados, 2012.

SILVA, Petronilha Beatriz Gonçalves e. Aprender, Ensinar e Relações Étnico-raciais no Brasil. In: Educação. Porto Alegre: Pontifícia Universidade Católica do Rio Grande do Sul, v. 30, n 3. 2007. Disponível Em: <http://revistaseletronicas.pucrs.br/ojs/index.php/faced/article/ view/2745 >. Acesso em: 15 jan. 2020. 